\title{
A new tubeworm of possible serpulid affinity from the Permian of Sicily
}

\author{
Rossana Sanfilippo, Agatino Reitano, Gianni Insacco, and Antonietta Rosso \\ Acta Palaeontologica Polonica 61 (3), 2016: 621-626 doi:http://dx.doi.org/10.4202/app.00209.2015
}

A new tubeworm, Palaeotubus sosiensis gen. et sp. nov., is described from the Permian Pietra di Salomone limestone (Sosio Valley, W Sicily). The new species is characterized by a thick tube ornamented with slightly flared peristomes and numerous longitudinal keels. The internal structure of the tube was obliterated during diagenesis, which prevents the tube unequivocal systematic attribution. Nevertheless, all preserved morphological characters strongly suggest that the new tube belongs to serpulids. When confirmed by further findings, the positive attribution of this new species to serpulids will imply that it represents the ancestor of the Serpulidae, and the earliest evidence of calcareous tubeworm polychaetes from the Palaeozoic.

Rossana Sanfilippo [sanfiros@unict.it] and Antonietta Rosso [rosso@unict.it], Department of Biological, Geological and Environmental Sciences, University of Catania, Corso Italia 57, Catania, Italy. Agatino Reitano [tinohawk@ yahoo.it ] and Gianni Insacco [g.insacco@comune.comiso.rg.it], Museo Civico di Storia Naturale di Comiso, Via degli Studi 9, 97013 Comiso, Italy.

This is an open-access article distributed under the terms of the Creative Commons Attribution License (for details please see creativecommons.org), which permits unrestricted use, distribution, and reproduction in any medium, provided the original author and source are credited.

FaF Full text $(511.5 \mathrm{kB})$ 